Authors have nothing to disclose with regard to commercial support.

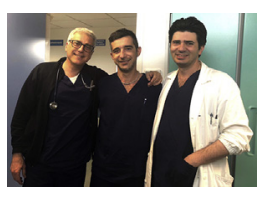

\section{AORTIC VALVE IMPLANTATION OR REPLACEMENT: WHICH PROCEDURE IS MORE COST- EFFECTIVE?}

\section{To the Editor:}

Cost-effectiveness analysis of a procedure is always difficult because of the many factors involved and the quantification of costs to achieve the desired outcome. In particular, the new devices for transcatheter aortic valve implantation (TAVI) are increasingly compared with traditional prostheses, not only in terms of clinical outcome but also in terms of costs, because of the more expensive technology required.

Although this minimally invasive procedure has been reported to reduce length of hospital stay, transfusions, and hence total costs, the higher price of TAVI prostheses makes this procedure less cost-effective than traditional surgery. ${ }^{1}$ Additionally, in countries where a reimbursement system for TAVI procedures is established, this treatment is almost always disadvantageous for the facility performing this procedure under the cost reimbursement plan.

Recently, in an analysis Tam and colleagues ${ }^{2}$ concluded that TAVI procedures would be more cost-effective than traditional surgery in intermediate-risk patients. However, also considering previous analyses, these results are still open to debate.

First, a comment should be made on the selection of patients: the results are derived from the Placement of Aortic Transcatheter Valves (PARTNER) 2 trial, whereas, for cost-effectiveness analyses, data should be obtained as much as possible from "real-life" settings rather than from randomized clinical trials. Second, the effect of paravalvular leak is completely neglected, which is an independent predictor of mortality, as also shown in the PARTNER trial. If paravalvular leak had been considered by the authors, no positive delta for quality-adjusted

\footnotetext{
The Editor welcomes submissions for possible publication in the Letters to the Editor section that consist of commentary on an article published in the Journal or other relevant issues. Authors should: $\bullet$ Include no more than 500 words of text, three authors, and five references. • Type with double-spacing. • See http://jtcs.ctsnetjournals.org/ misc/ifora.shtml for detailed submission instructions. • Submit the letter electronically via jtcvs.editorialmanager.com. Letters commenting on an article published in the JTCVS will be considered if they are received within 6 weeks of the time the article was published. Authors of the article being commented on will be given an opportunity of offer a timely response ( 2 weeks) to the letter. Authors of letters will be notified that the letter has been received. Unpublished letters cannot be returned.
}

life-years or life years in favor of TAVI could be found, and the Kaplan-Meier estimates at 2 years would have been very different for the TAVI arm. The same information on costs deserves better understanding: in the report of Tam and colleagues, the costs are $\$ 24,000$ and $\$ 6000$ for TAVI and surgery, respectively, but these were previously presented at the Transcatheter Cardiovascular Therapeutics conference 2017 as $\$ 32,500$ and $\$ 5000$, respectively. A difference of almost $\$ 10,000$ is not negligible! Moreover, other costs should be taken into consideration for TAVI, which is the cost of the on-call cardiac team not included by the authors, and the specific analyses for patient preparation (eg, computed tomography scan, angiography) calculated at $\$ 119$, which seems somewhat underestimated. In summary, the costeffectiveness of surgical procedures versus TAVI is still an open issue and, at present, the only certainties seem to be the significantly higher cost of TAVI prostheses and the dependence of cost-effectiveness on the health system within which the procedure is performed.

$$
\begin{array}{r}
\text { Giuseppe Santarpino, } M D^{a, b} \\
\text { Luigi Specchia, } M D^{b} \\
\text { Luigi Lombardi, } M D^{b} \\
{ }^{a} \text { Paracelsus Medical University } \\
\text { Nuremberg, Germany } \\
{ }^{b} \text { Città di Lecce Hospital-GVM Care \& Research } \\
\text { Lecce, Italy }
\end{array}
$$

\section{References}

1. Santarpino G, Pfeiffer S, Jessl J, Dell'Aquila A, Vogt F, von Wardenburg C, et al. Clinical outcome and cost analysis of sutureless versus transcatheter aortic valve implantation with propensity score matching analysis. Am J Cardiol. 2015;116:1737-43.

2. Tam DY, Hughes A, Fremes SE, Youn S, Hancock-Howard RL, Coyte PC, et al. A cost-utility analysis of transcatheter versus surgical aortic valve replacement for the treatment of aortic stenosis in the population with intermediate surgical risk. J Thorac Cardiovasc Surg. 2018;155:1978-88.

\section{https://doi.org/10.1016/j.jtcvs.2018.05.031}

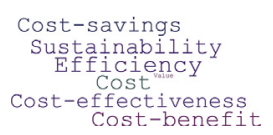

\section{COST AND \\ EFFECTIVENESS: \\ CAN'T HAVE ONE \\ WITHOUT THE OTHER \\ Reply to the Editor:}

We thank Dr Santarpino

and colleagues ${ }^{1}$ for their interest in our cost-utility analysis comparing the cost-effectiveness of transcatheter aortic valve implantation (TAVI) with surgical aortic valve replacement (SAVR) in intermediate surgical risk patients. ${ }^{2}$ By adapting randomized clinical trial (RCT) data from the Placement of Transcatheter Aortic Valves (PARTNER) 2 study, we showed that TAVI might be cost-effective compared with SAVR at commonly used willingness-to-pay thresholds. ${ }^{3}$ 